\section{Gategory}

Synthesis of

Materials and

Unnatural Products

\section{Key words}

\section{desulfurization}

organic salts

sulfones

superacids

thiophenes
T. SAKAI, * S. SEO, J. MATSUOKA, Y. MORI* (MEIJO UNIVERSITY, NAGOYA, JAPAN) Synthesis of Functionalized Tetracyanocyclopentadienides from Tetracyanothiophene and Sulfones J. Org. Chem. 2013, 78, 10978-10985.

\title{
Superacid Anions from Tetracyanothiophene
}

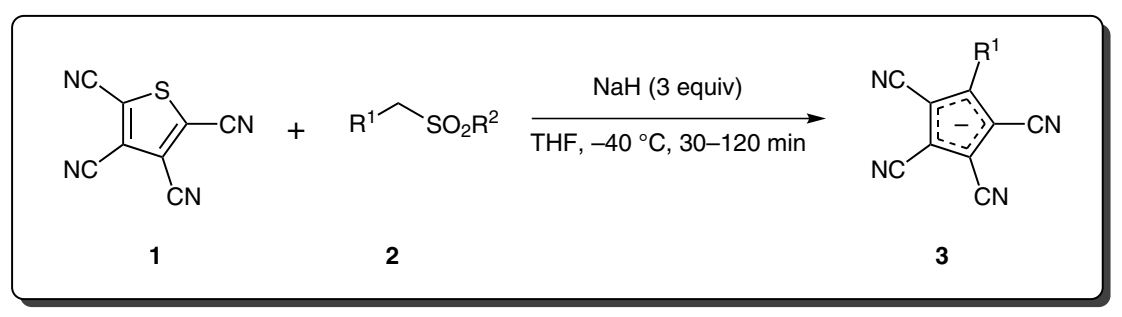

\begin{tabular}{ccccc} 
Entry & $\mathrm{R}^{1}$ & $\mathrm{R}^{2}$ & Product & Yield (\%) \\
\hline 1 & $\mathrm{CO}_{2} \mathrm{Me}$ & $\mathrm{Ph}$ & $\mathbf{3 a}$ & 59 \\
2 & $\mathrm{CN}$ & $\mathrm{Tol}$ & $\mathbf{3 b}$ & 96 \\
3 & $\mathrm{CONMe}(\mathrm{OMe})$ & $\mathrm{Tol}$ & $\mathbf{3 c}$ & 86 \\
4 & $\mathrm{Ph}$ & $\mathrm{Ph}$ & $\mathbf{3 d}$ & 15 \\
5 & $\mathrm{Ph}$ & $\mathrm{CF}_{3}$ & $\mathbf{3 e}$ & 71 \\
6 & $\mathrm{CH}_{2} \mathrm{CH}_{2} \mathrm{OBn}$ & $\mathrm{CF}_{3}$ & $\mathbf{3 f}$ & 61
\end{tabular}

\section{Proposed mechanism:}

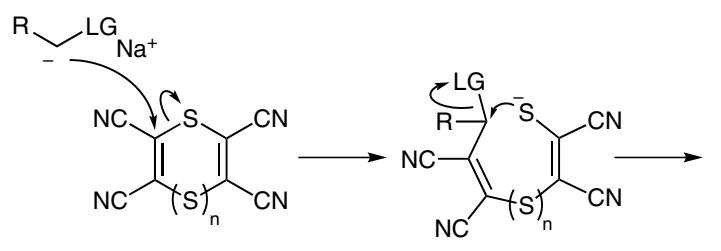

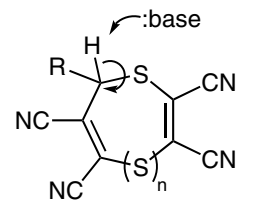<smiles>N#Cc1sc(N)c(C#N)c1C#N</smiles><smiles>N#Cc1c([N+]#N)c(C#N)c([N+]#N)c([N+]#N)c1[N+]#N</smiles>

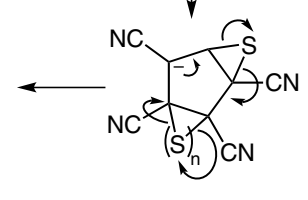

Significance: The authors report an improved synthesis of tetracyanocyclopentadienyl anions, a class of superacid anions with functional handles. By including the leaving group on the nucleophile, product $\mathbf{3}$ is accessed more directly from thiophene $\mathbf{1}$ and sulfone $\mathbf{2}$. The researchers demonstrate the reaction's utility with a variety of sulfones and successful exchange of cations.
Comment: Optimization of the reaction conditions revealed a strong dependence on base, with $\mathrm{NaH}$ outperforming alkoxide, silazide, and non-ionic nitrogen bases. Using phenylsulfones as the leaving groups proved more facile than using halides. Ketones could not be directly synthesized with this method but can be obtained from the Weinreb amide derivative $\mathbf{3 c}$. 